\title{
Multifrequency Piezoelectric Energy Harvester Based on Polygon-Shaped Cantilever Array
}

\author{
Dalius Mažeika $\left(\mathbb{D},{ }^{1}\right.$ Andrius Čeponis $\mathbb{D}^{1},{ }^{1}$ and Ying Yang ${ }^{2}$ \\ ${ }^{1}$ Vilnius Gediminas Technical University, Saulètekio Avn. 11, LT-10223 Vilnius, Lithuania \\ ${ }^{2}$ Nanjing University of Aeronautics and Astronautics, 29 Yudao Street, P.O. Box 359, Nanjing, Jiangsu 210016, China \\ Correspondence should be addressed to Dalius Mažeika; dalius.mazeika@vgtu.lt
}

Received 25 August 2017; Revised 3 December 2017; Accepted 11 January 2018; Published 8 March 2018

Academic Editor: Michele Magno

Copyright (C) 2018 Dalius Mažeika et al. This is an open access article distributed under the Creative Commons Attribution License, which permits unrestricted use, distribution, and reproduction in any medium, provided the original work is properly cited.

\begin{abstract}
This paper focuses on numerical and experimental investigations of a novel design piezoelectric energy harvester. Investigated harvester is based on polygon-shaped cantilever array and employs multifrequency operating principle. It consists of eight cantilevers with irregular design of cross-sectional area. Cantilevers are connected to each other by specific angle to form polygonshaped structure. Moreover, seven seismic masses with additional lever arms are added in order to create additional rotation moment. Numerical investigation showed that piezoelectric polygon-shaped energy harvester has five natural frequencies in the frequency range from $10 \mathrm{~Hz}$ to $240 \mathrm{~Hz}$, where the first and the second bending modes of the cantilevers are dominating. Maximum output voltage density and energy density equal to $50.03 \mathrm{mV} / \mathrm{mm}^{3}$ and $604 \mu \mathrm{J} / \mathrm{mm}^{3}$, respectively, were obtained during numerical simulation. Prototype of piezoelectric harvester was made and experimental investigation was performed. Experimental measurements of the electrical characteristics showed that maximum output voltage density, energy density, and output power are $37.5 \mathrm{mV} / \mathrm{mm}^{3}, 815.16 \mu \mathrm{J} / \mathrm{mm}^{3}$, and $65.24 \mu \mathrm{W}$, respectively.
\end{abstract}

\section{Introduction}

Modern electronic and mechatronic systems have high demand on wireless sensors, low-power electronic devices, and wireless data transfer systems. In general, such devices are used to control numerous physical parameters to store and transfer data wirelessly $[1,2]$. Usually electric power for the aforementioned electronic devices is delivered by electrochemical batteries that have numerous disadvantages such as short lifetime, high costs of maintenance, and being unfriendly for the environment. Therefore, novel power supply technologies must be applied to the wireless and lowpower electronic systems [3, 4].

Nowadays, energy harvesting technologies can be successfully used as an alternative solution to the electrochemical batteries. However, a proper energy harvesting technology must be chosen to obtain the highest efficiency of alternative power supply $[5,6]$. Therefore electromagnetic, electrostatic, and triboelectric harvesters were developed. However, all of these harvesters have low-power density, are expensive, and have complex structures. Moreover, external power supply is needed for operation of electrostatic harvesters. Therefore, practical application of these energy harvesting technologies is complicated or economically unacceptable $[7,8]$. On the other hand, piezoelectric energy harvesters are able to provide such features as high power density, long lifetime, and low costs of production and maintenance. Usually, design of piezoelectric energy harvesters is based on conventional cantilevers. Such type of the harvesters operates at the resonant frequency; as a result, the highest output power is achieved when natural frequency of the harvester matches with the vibration frequency of the host. It means that the output power of piezoelectric harvester depends on vibration frequency of the host; therefore operation bandwidth of the harvester must be increased to avoid this problem [9-11]. Two major principles are used to broaden frequency response range of the piezoelectric energy harvester, that is, nonlinear operation principle and multifrequency principle. Nonlinear behavior of piezoelectric energy harvester can be achieved by several active and passive techniques like stiffness tuning, axial preload, and magnetic coupling operation [12-15]. 
Wang et al. proposed magnetically coupled piezoelectric energy harvester with an elastic magnifier. Goal of the investigations was to overcome potential well barriers and to obtain much large-amplitude bistable motion. Numerical and experimental investigation confirmed that proposed energy harvesting system provides high output power, while mass/stiffness ratio of the harvester has the highest value. The maximum measured output power was $6.76 \mathrm{~mW}$ when resistance load of $100 \mathrm{k} \Omega$ was applied at excitation frequency of $17.6 \mathrm{~Hz}$. It is 26 times higher output power value compared to conventional energy harvester [16].

Jiang et al. analyzed a multistep piezoelectric buckled beam energy harvester. Magnetic forces generated by permanent magnets were used for excitation. Multistep mechanism was employed to increase bandwidth and power density of the piezoelectric energy harvesting system. Authors showed that proposed buckled beam system is able to provide highvoltage output at broadband excitation frequencies; that is, open-circuit voltage generated by energy harvester was $\pm 5.5 \mathrm{~V}$, while the maximum voltage of $\pm 9.3 \mathrm{~V}$ was achieved at $4.4 \mathrm{~Hz}$. Moreover, output power of the harvester reached $5.0 \mu \mathrm{W}$ when the load resistance was $3.3 \mathrm{M} \Omega$ [17].

Upadrashta and Yang introduced a new design of nonlinear piezomagnetoelastic energy harvester [18]. Nonlinearity was obtained by magnetic interaction between embedded magnet in the tip of each cantilever and the rigidly fixed magnet. Array of monostable cantilevers ensured $100 \mu \mathrm{W}$ output power at bandwidth of $3.3 \mathrm{~Hz}$.

Piezoelectric energy harvesters based on multifrequency operation principle can be used for wide bandwidth energy harvesting as well. Usually multifrequency energy harvesters consist of several cantilevers that can operate at different resonant frequencies. This type of the harvesters has simple design and usually has linear-type vibrations.

Zhou et al. investigated energy harvester based on multimode dynamic magnifier [19]. Investigation was focused on energy harvester which consisted of multimodal magnifier and simple cantilever with the seismic mass. Results of investigation revealed that proposed harvester is able to acquire 25.5 times larger amount of energy compared to the conventional cantilever in frequency range from $3 \mathrm{~Hz}$ to $300 \mathrm{~Hz}$. Moreover, authors showed that this particular device can harvest from 100 till 1000 times more energy while operating near the first three natural frequencies of the energy harvesting system.

Lee et al. designed and investigated a segmented-type harvester that employs multiple modes of harvester vibrations [20]. Results of investigation showed that the proposed harvester has two suitable resonant modes and the difference between resonant frequencies is relatively small. Moreover, authors claimed that electrical characteristics of the device are suitable to ensure power supply for industrial wireless temperature sensors used for building monitoring systems.

Qi et al. investigated a clamped-clamped type piezoelectric energy harvester with side mounted cantilevers [21]. Numerical and experimental investigations revealed that investigated system has five natural frequencies that were located at the narrow frequency range. Authors claimed that proposed harvester is able to exhibit broadband frequency response. Also, authors concluded that obtained summation of the modal strains improved efficiency of the harvester at wide frequency range and ensured true broadband energy harvesting.

Rezaeisaray et al. published results of investigation about piezoelectric micro energy harvester with multiple degrees of freedom [22]. Based on results of investigation, it was shown that proposed design of the harvester has three natural frequencies at frequency range from $71 \mathrm{~Hz}$ to $189 \mathrm{~Hz}$. Authors claimed that maximum open-circuit voltage and output power reached $1 \mathrm{~V}$ and $136 \mathrm{nW}$, respectively, when load resistance was $2 \mathrm{M} \Omega$. These electrical characteristics were obtained when excitation amplitude was $0.2 \mathrm{~g}$, while excitation frequency was $97 \mathrm{~Hz}$.

Toyabur et al. investigated a multimodal vibration energy harvester with multiple piezoelectric elements [23]. Proposed design of the harvester consists of four piezoelectric modules and has four natural frequencies at frequency region from $10 \mathrm{~Hz}$ to $20 \mathrm{~Hz}$. Based on results of investigation, authors claimed that one module is able to provide $249.78 \mu \mathrm{W}$ peak power under $0.4 \mathrm{~g}$ of base acceleration. Authors concluded that parallel connection of the modules can ensure four times higher output power and generate much higher power at every vibration mode.

Dhote et al. designed and investigated a multimode piezoelectric energy harvester based on a trileg compliant orthoplanar spring with multiple masses [24]. Random excitation of the harvester revealed that it has three natural frequencies with values lower than $150 \mathrm{~Hz}$. Also, the authors claimed that proposed device is able to harvest energy under random vibrations. Authors concluded that analyzed harvester has nonlinear multimode vibrations and is able to harvest energy from random environmental vibrations.

A new polygon-shaped multifrequency piezoelectric energy harvester is proposed in this paper. Special design of the harvester ensures modal strain summation and multifrequency energy harvesting. Irregular design of the crosssectional areas of the cantilevers and special design of the seismic masses improve strain distribution characteristic along the cantilevers length. Strain summation and advanced design of the proposed piezoelectric harvester allow increasing electrical output power of the energy harvesting system significantly.

\section{Design of Polygon-Shaped Energy Harvester}

Design of polygon-shaped cantilever array consists of eight piezoelectric cantilevers with irregular cross-sectional design, seven seismic masses, and a clamping system (Figure 1). The number of the cantilevers was influenced by demand to create two polygon-shaped systems with different stiffness within the same indissoluble energy harvesting device and to increase number of natural frequencies in specific frequency range. Such solution gives an opportunity to obtain modal strain summation at different vibration frequencies. Irregular design of cross-sectional areas of the cantilevers was caused by two goals, that is, to increase strain characteristics and to improve strain distribution characteristics along the cantilevers. The polygon-shaped 


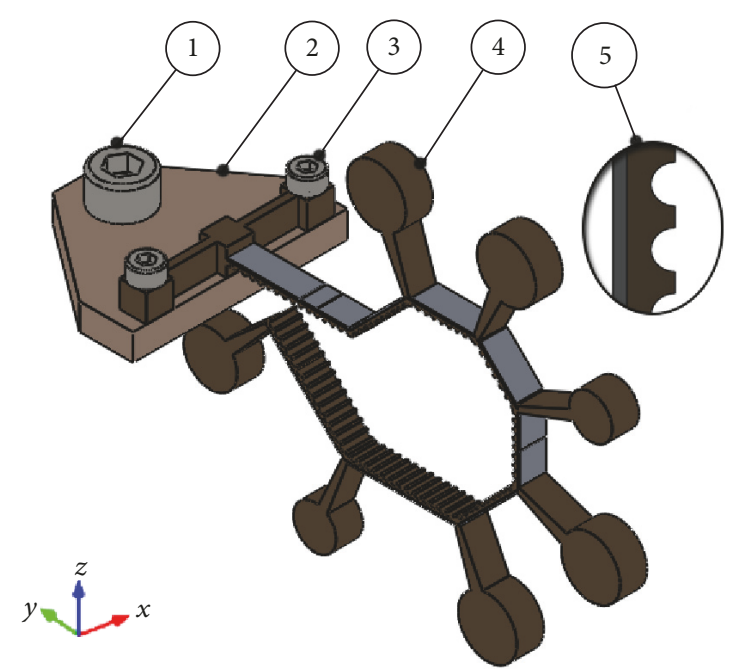

FIGURE 1: Isometric view of the energy harvester: (1) clamping bolt; (2) clamping frame; (3) M3 bolts for junction between the clamping frame and the harvester; (4) body of the polygon-shaped harvester; (5) design of cross-sectional area.

energy harvester has seven seismic masses placed at every corner of the harvester's body. A junction between seismic masses and the harvester was made by lever arms. Design of such seismic masses was introduced in order to create an additional rotation moment and to increase strain in the piezoceramic layers. Hence, an additional rotation moment and irregular design of cross-sectional areas allow obtaining almost liner function of the strain distribution along the length of the cantilevers.

Clamping frame serves as the coupling system between the body of harvester and the host (Figure 2). Two bolts are used to clamp energy harvester to the clamping frame. Two supporting beams are rigidly connected to the body of energy harvester and serve as connection between the body of energy harvester and clamping frame. Dimensions of the supporting beams are designed so that vibration of the first out of plane bending mode is excited when displacement of the harvester in $y$ direction is generated. Such design of the supporting beams allows avoiding structural damping of the harvester vibrations.

\section{Numerical Investigation of the Polygon-Shaped Energy Harvester}

Numerical investigation of the polygon-shaped energy harvester was divided into two parts. At the beginning, numerical investigation was performed to calculate optimal geometrical parameters of the cantilevers; after that mechanical and electrical characteristics of the harvester were investigated. Modal-frequency analysis and harmonic response analysis were studied. Finite element model (FEM) was built using Comsol 5.2 software. Boundary conditions were set as follows: ends of the supporting beams were fixed rigidly; motion of the host structure was modeled as acceleration of the harvester base in $z$ direction. Material properties used to build FEM model are given in Table 1. Principle scheme of the harvester is shown in Figure 3.

Two optimization problems were solved sequentially in order to obtain optimal design of the harvester. Goal of the first optimization problem was to find optimal length of the cantilevers when sum of the square differences of the neighboring resonant frequencies of the harvester is minimized. The resonant frequencies dominated by the first and the second out of plane vibration modes of any cantilever were used. Lengths of the eight cantilevers were chosen as the design variables and optimization problem was formulated as follows:

$$
\begin{aligned}
\min _{L} & \sum_{i=1}^{n-1}\left(w_{i+1}(L)-w_{i}(L)\right)^{2}, \\
\text { subject to } & l_{\min } \leq l_{i} \leq l_{\max } \\
& w_{\min } \leq w_{i} \leq w_{\max }, \\
& i=1, \ldots, 8 ;
\end{aligned}
$$

here $L=\left(l_{1}, \ldots, l_{8}\right)$ is a vector of cantilever lengths; $w_{i}$ is resonant frequency of the harvester dominated by the first vibration mode of any cantilever; $l_{\min }$ and $l_{\max }$ are the minimal and the maximal values of the cantilever length; $n$ is the number of cantilevers and is equal to 8 .

Goal of the second optimization problem was to obtain optimal mass values of the seismic masses in order to maximize tip displacement of the harvester in $z$ direction. It was solved after the optimal length of the cantilevers was obtained. Optimization problem was formulated as follows:

$$
\begin{aligned}
\max _{M} & \left(u_{z}(M)\right), \\
\text { subject to } & m_{\min } \leq m_{i} \leq m_{\max }, \quad i=1, \ldots, 7 ;
\end{aligned}
$$

here $M=\left(m_{1}, \ldots, m_{7}\right)$ is a vector of seismic mass weights; $u_{z}$ is harvester tip displacement in $z$ direction; $m_{\min }$ and $m_{\max }$ are the minimal and the maximal mass values of the seismic masses.

Both optimization problems were solved by frequency domain studies using linear search method. Acceleration of the base was set to $0.5 \mathrm{~m} / \mathrm{s}^{2}$. Values of $l_{\min }$ and $l_{\max }$ were set to $10 \mathrm{~mm}$ and $25 \mathrm{~mm}$, respectively, while length iteration step was $1 \mathrm{~mm}$. Values of $m_{\min }$ and $m_{\max }$ were set to 2.5 grams and 5 grams, respectively, while step was 0.1 grams. The frequency range for both optimization problems was stated from $w_{\min }=$ $10 \mathrm{~Hz}$ to $w_{\max }=450 \mathrm{~Hz}$. Obtained optimized parameters of the harvester are listed in Table 2.

The second part of numerical investigation was dedicated to analyzing mechanical and electrical characteristics of the harvester. Geometrical parameters of the harvester were stated with respect to the values obtained during optimization study. Modal analysis of the harvester was performed in order to indicate natural frequencies and modal shapes of the harvester (Figure 4). Analysis of the results revealed that energy harvester has five natural frequencies at the range from $10 \mathrm{~Hz}$ to $240 \mathrm{~Hz}$. It can be noticed that the first and the second out of plane bending modes of the cantilevers are dominating in the 
TABLE 1: Material properties.

\begin{tabular}{lcc}
\hline Material properties & $\begin{array}{c}\text { Beryllium } \\
\text { bronze } \\
\text { C17200 }\end{array}$ & Piezoceramic PIC255 \\
\hline Density $\left[\mathrm{kg} / \mathrm{m}^{3}\right]$ & 8360 & 7800 \\
\hline Elastic modulus $\left[\mathrm{kg} / \mathrm{mm}^{2}\right]$ & $13.4 \cdot 10^{10}$ & - \\
\hline Poisson's ratio & 0.34 & - \\
\hline Isotropic structural loss factor & 0.02 & 0.015 \\
\hline & - & In the polarization direction \\
& $\varepsilon_{33}{ }^{10} / \varepsilon_{0}=1200$ \\
Relative permittivity & Perpendicular to polarity \\
& $\varepsilon_{11}{ }^{T} / \varepsilon_{0}=1500$ \\
\hline Elastic stiffness coefficient $c_{33} D\left[\mathrm{~N} / \mathrm{m}^{2}\right]$ & - & $16.6 \cdot 10^{10}$ \\
\hline Dielectric loss factor, tan $\delta\left[10^{-3}\right]$ & - & 20 \\
\hline Coupling factor, $k_{31}$ & - & 0.35 \\
\hline Piezoelectric voltage coefficient, $g_{31}\left[10^{-3} \mathrm{Vm} / \mathrm{N}\right]$ & -11.3 \\
\hline
\end{tabular}

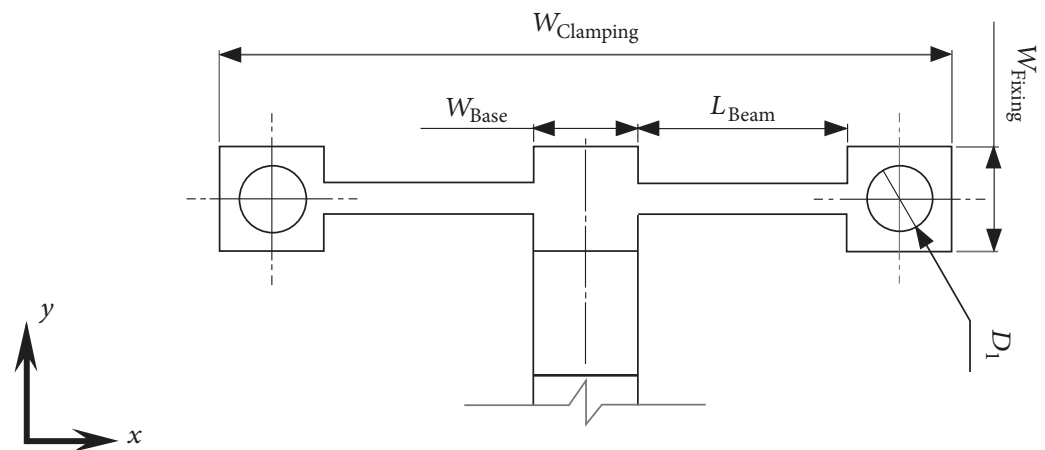

FIGURE 2: Scheme of the clamping system: $W_{\text {Clamping }}-35 \mathrm{~mm} ; W_{\text {Base }}-5 \mathrm{~mm} ; L_{\text {Beam }}-10 \mathrm{~mm} ; W_{\text {Fixing }}-10 \mathrm{~mm} ; D_{1}-3.2 \mathrm{~mm}$.

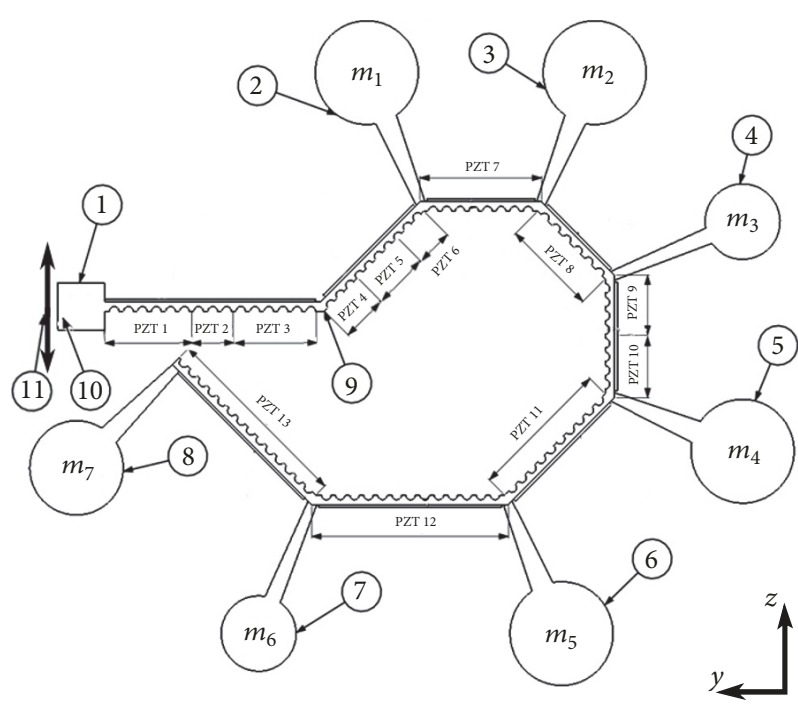

FIGURE 3: Principle scheme of the piezoelectric polygon-shaped energy harvester: (1) base of harvester; (2)... (8) seismic masses (C17200 beryllium bronze); $\mathrm{PZT}_{1} \cdots \mathrm{PZT}_{13}$ : piezoceramic layers (PIC255); (9) body of harvester (C17200 beryllium bronze); (10) fixed constrain; (11) direction of the excitation.
TABLE 2: Optimized parameters of the harvester.

\begin{tabular}{lccc}
\hline Parameter & Value, $\mathrm{mm}$ & Parameter & Value, $\mathrm{g}$ \\
\hline$l_{1}$ & 23 & $m_{1}$ & 4.6 \\
$l_{2}$ & 15 & $m_{2}$ & 4.6 \\
$l_{3}$ & $m_{3}$ & 2.7 \\
$l_{4}$ & 13 & $m_{4}$ & 4.6 \\
$l_{5}$ & 11 & $m_{5}$ & 4.6 \\
$l_{6}$ & 13 & $m_{6}$ & 2.7 \\
$l_{7}$ & 16 & $m_{7}$ & 3.9 \\
$l_{8}$ & 2 & & \\
\hline
\end{tabular}

obtained modal shapes of the harvester. This study showed that the number of the natural frequencies in the analyzed frequency range is sufficient for the multifrequency energy harvesting.

Mechanical and electrical characteristics of the harvester were investigated at the frequency range of $10-240 \mathrm{~Hz}$. Base acceleration amplitude was set to $0.5 \mathrm{~m} / \mathrm{s}^{2}$. Amplitude graph of harvester tip acceleration in $z$ direction versus frequency is shown in Figure 5. 


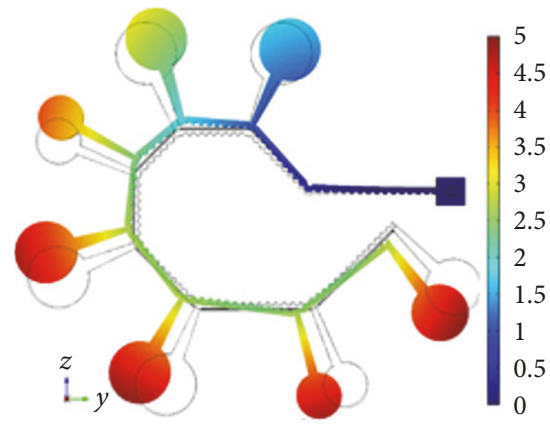

(a)

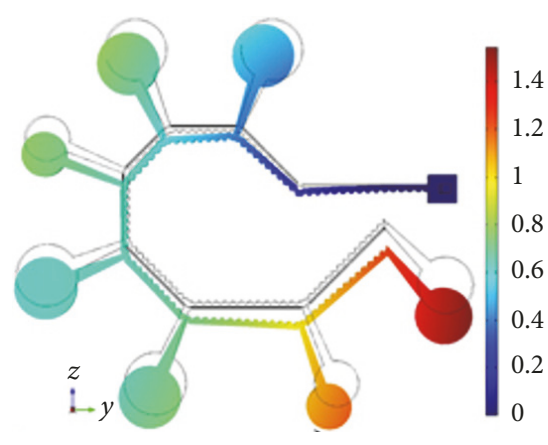

(b)

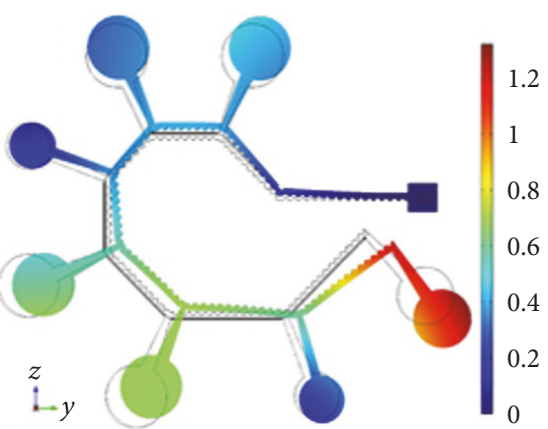

(c)

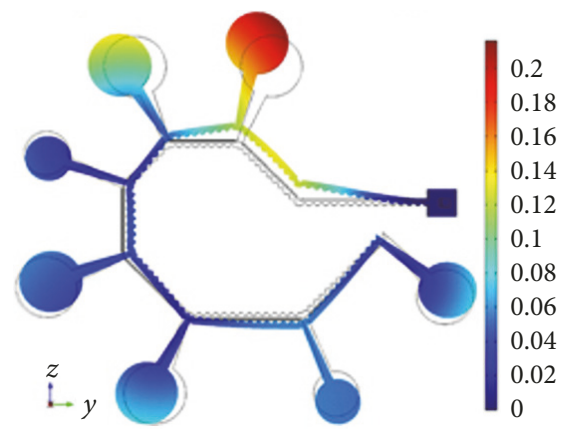

(d)

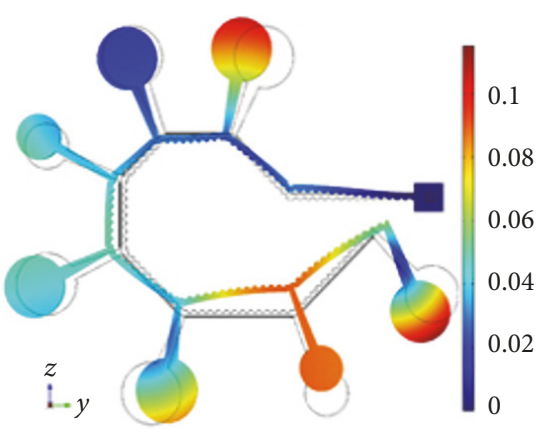

(e)

Figure 4: Modal shapes of the harvester: (a) $14.41 \mathrm{~Hz}$; (b) $25.926 \mathrm{~Hz}$; (c) $73.981 \mathrm{~Hz}$; (d) $199.53 \mathrm{~Hz}$; (e) $214.56 \mathrm{~Hz}$.

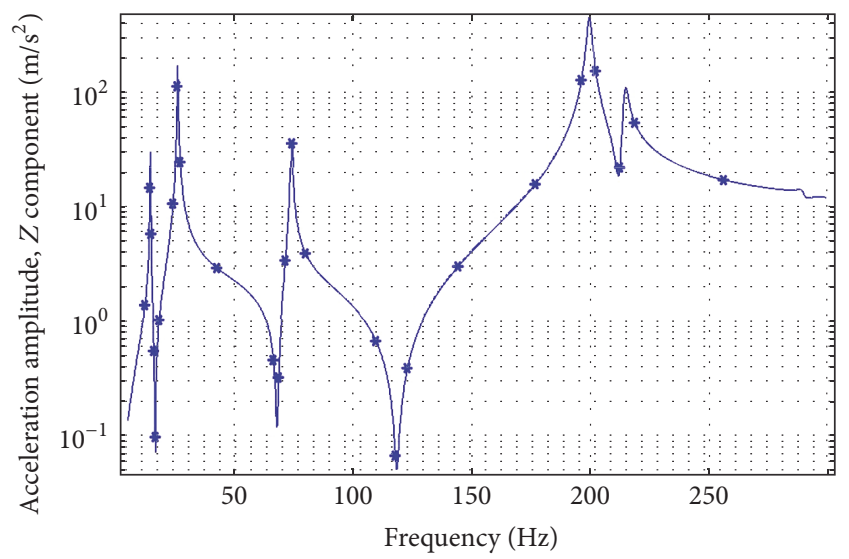

FIGURE 5: Acceleration amplitude versus excitation frequency.

Analysis of the frequency response characteristic confirmed results of the modal analysis. Resonant frequencies have good coincidence with the natural frequencies obtained during modal analysis. Obtained characteristic showed that the first three resonant frequencies are located at the narrow frequency range and are close to each other. It shows that energy harvester will be able to operate efficiently at this frequency range. On the other hand, 4th and 5th resonant frequencies are located at slightly higher frequencies. However, these resonant frequencies are adequately close to each other and provide multifrequency energy harvesting at that frequency range. Moreover, high acceleration amplitude of the energy harvester tip at the resonance frequencies has positive influence on the electrical characteristics of harvester.

Investigation of strain distribution along each cantilever was performed as well. Results of the calculations are given in Figure 6. It can be seen that, in most cases, strain distribution characteristics are almost liner and constant along the length of the cantilever except the cases when the second or higher vibration modes occur at the cantilevers. Almost linear strain characteristic was achieved by modifications made to the cross-sectional areas and special design of the seismic masses. Modifications of cross-sectional areas improved strain distribution, while special design of the seismic masses ensured higher values of the strain.

Electrode configuration of piezoceramic layers was based on the strain distribution along the length of the beam. Electrode configuration allowed proper separation of positive and negative charges obtained when cantilevers of the harvester vibrate at the second vibration mode. Proper electrode configuration influences electrical output characteristics of multifrequency energy harvester. Algorithm of electrode configuration was formulated as follows: partitioning of the electrodes was made in the places where the value of stain tensor component is close to zero. Therefore, five vibration nodes of the harvester were analyzed and partitioning of the electrodes was made at indicated nodes. As a result, thirteen different electrodes $\left(\mathrm{PZT}_{1}-\mathrm{PZT}_{13}\right)$ were composed on the top surfaces of the piezoceramic layers of the harvester (Figure 2).

Investigation of electrical characteristics was performed as well. Mechanical boundary conditions of the harvester 


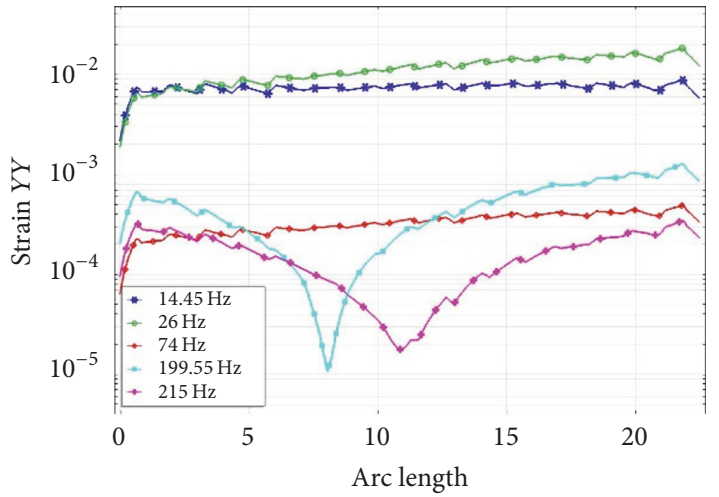

(a)

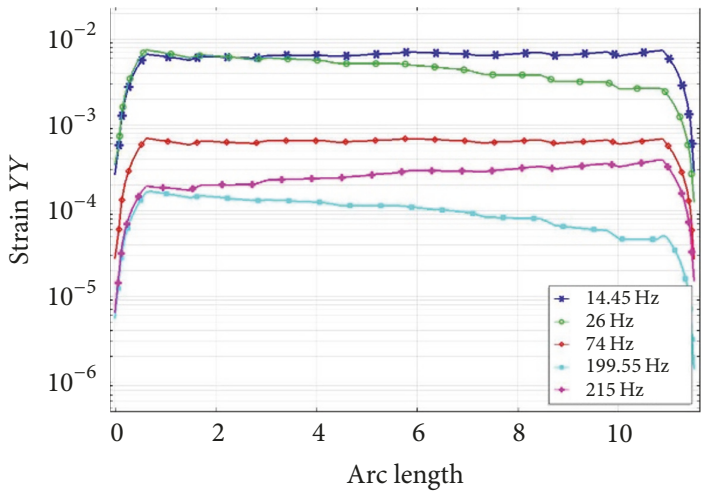

(c)

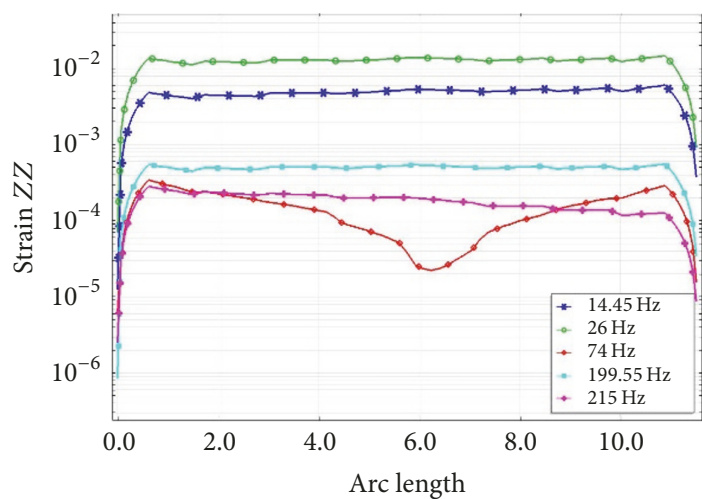

(e)

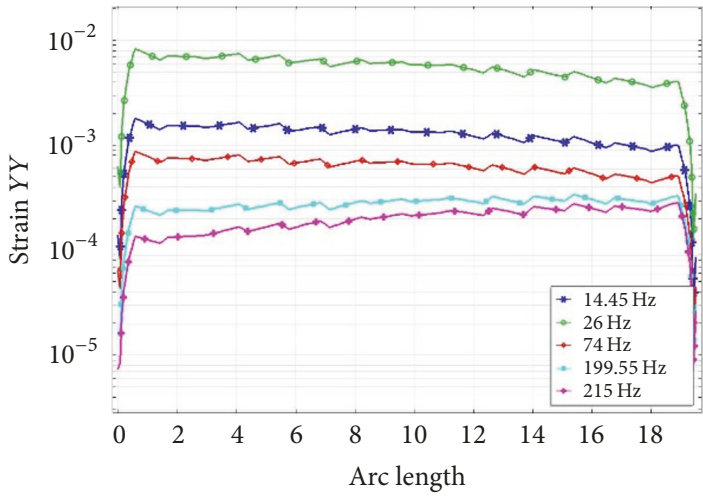

(g)

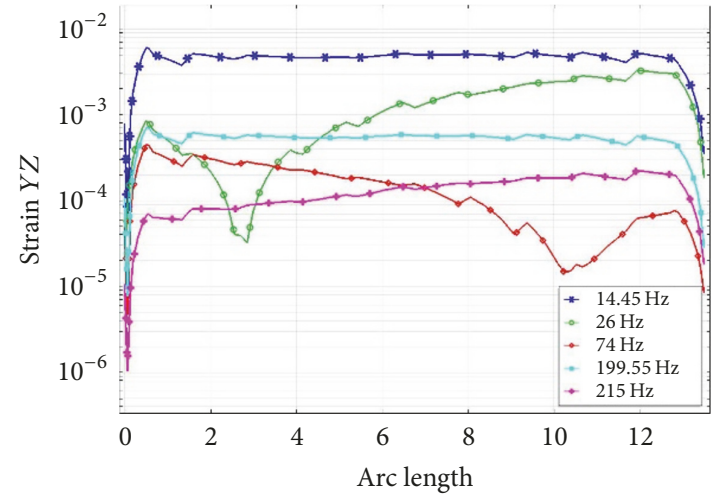

(b)

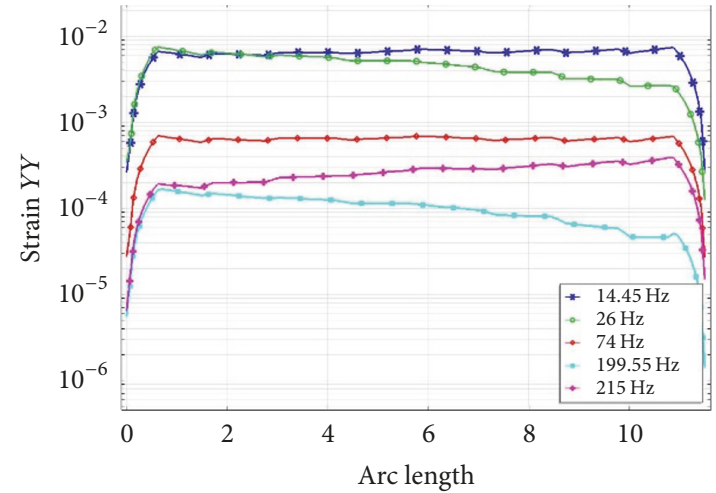

(d)

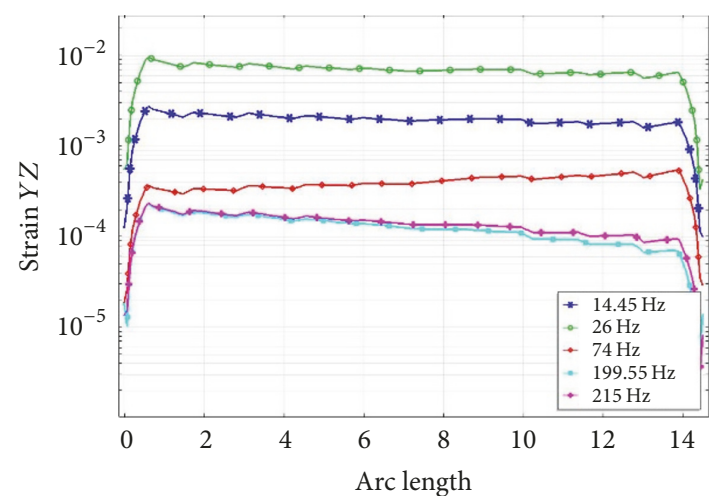

(f)

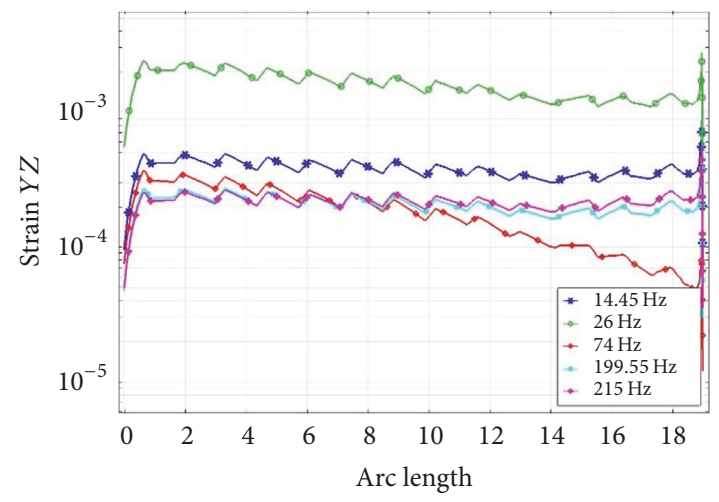

(h)

FIGURE 6: Strain characteristics at the cantilevers; (a) at $L_{1}$; (b) at $L_{2} ;$ (c) at $L_{3} ;$ (d) at $L_{4} ;$ (e) at $L_{5} ;$ (f) at $L_{6}$; (g) at $L_{7} ;$ (h) at $L_{8}$. 
were the same as in the previous numerical investigation. Electrodes were connected in parallel in order to increase the charge value during harvester operation. The aims of investigation were to obtain output voltage density and energy density characteristics in frequency domain. Voltage density and energy density were introduced in order to compare electrical characteristics of the harvester at the different resonant frequencies. Voltage density can be expressed as follows:

$$
U_{\sigma}=\frac{U_{\text {output }}}{W_{\mathrm{PZT}} \cdot h_{\mathrm{PZT}} \cdot \sum_{i=1}^{i=j-1} \mathrm{PZT}_{i}} ;
$$

here $U_{\sigma}$ is voltage density of the harvester; $U_{\text {output }}$ is output voltage of the harvester; $\mathrm{PZT}_{i}$ is length of piezoceramic layer; $W_{\mathrm{PZT}}$ is width of piezoceramic layer; $h_{\mathrm{PZT}}$ is height of piezoceramic layer; $j$ is number of piezoceramic layers (Figure 3).

Energy density of the harvester was calculated as follows:

$$
E_{\sigma}=\frac{E_{\text {output }}}{W_{\mathrm{PZT}} \cdot h_{\mathrm{PZT}} \cdot \sum_{i=1}^{i=j-1} \mathrm{PZT}_{i}} ;
$$

here $E_{\sigma}$ is voltage density of the harvester; $E_{\text {ouput }}$ is output voltage of the harvester; $\mathrm{PZT}_{i}$ is length of piezoceramic layer; $W_{\mathrm{PZT}}$ is width of piezoceramic layer; $h_{\mathrm{PZT}}$ is height of piezoceramic layer; $j$ is number of piezoceramic layers (Figure 3).

Numerical investigation of the voltage density was performed while applying open-circuit boundary conditions. The results of calculations are given in Figure 7. It can be seen that peaks of voltage density and energy density were obtained at the resonant frequencies. The highest voltage density was obtained at the 2 nd resonant frequency and it reached $50.03 \mathrm{mV} / \mathrm{mm}^{3}$. Other values of voltage density are lower. However, it shows high electrical potential of the energy harvester. Ratio between the highest voltage density and the lowest voltage density is 6.78. It shows that voltage density is sensitive to the resonant frequency mode. However, several voltage density peaks at narrow frequency range give an opportunity to obtain multifrequency-type energy harvesting.

Analysis of energy density characteristic showed that energy harvester is able to provide acceptable energy feed at the different resonant frequencies. The highest energy density was obtained at the 2 nd resonant frequency as well. Maximum value of the energy density reached $604 \mu \mathrm{J} / \mathrm{mm}^{3}$. In addition, it must be mentioned that energy density reached high value, $481 \mu \mathrm{J} / \mathrm{mm}^{3}$, at the 1st resonant frequency as well. Therefore, it can be concluded that energy harvester is able to provide high energy feed with overcapacity at the two different resonant frequencies. On the other hand, energy feed at the other resonant frequencies is much lower. It can be concluded that the highest efficiency of energy harvester will be achieved at the lower frequency, while operation at the higher frequency is less effective, but energy feed is appreciable.

Comparison of voltage density and energy density values was made in order to assess electrical characteristics

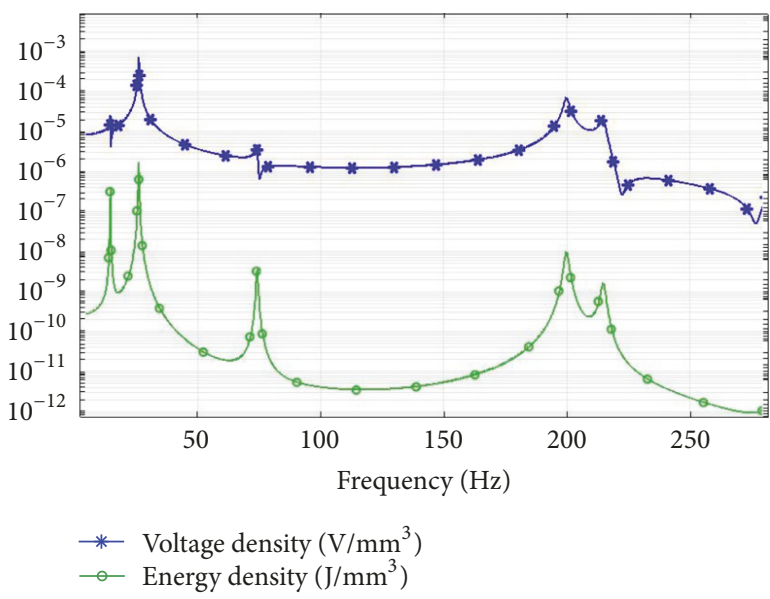

FIGURE 7: Electrical characteristics of the harvester.

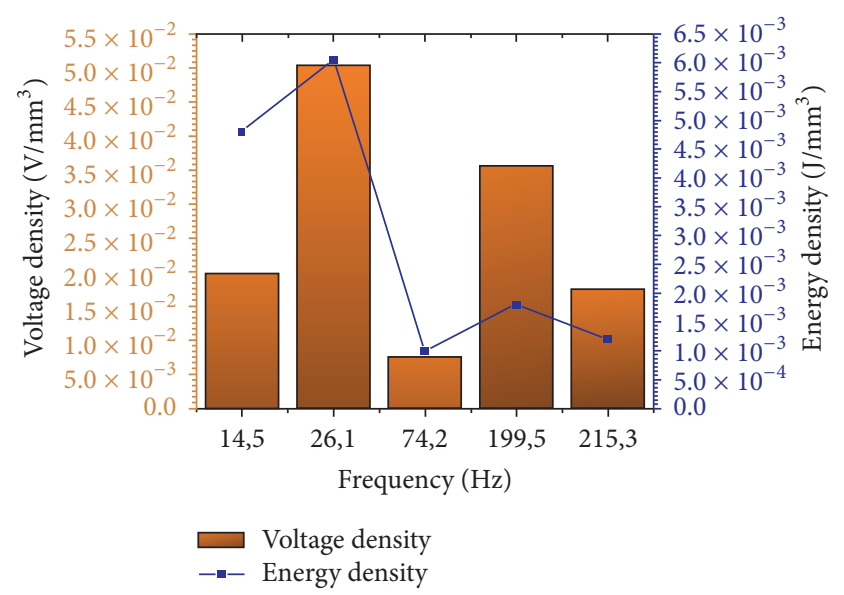

FIGURE 8: Summary of electrical characteristics of the harvester.

of the energy harvester at different resonant frequencies (Figure 8). Based on obtained results, it can be concluded that voltage and energy densities vary from $7.5 \mathrm{mV} / \mathrm{mm}^{3}$ to $50.03 \mathrm{mV} / \mathrm{mm}^{3}$ and from $120 \mu \mathrm{J} / \mathrm{mm}^{3}$ to $604 \mu \mathrm{J} / \mathrm{mm}^{3}$, respectively. It is shown that values of voltage and energy densities are obtained at wide range, but harvester is not able to provide constant voltage and energy at the different excitation frequencies. On the other hand, when comparing minimum values of the conventional cantilever array with the proposed multifrequency harvester, it can be noticed that the higher output values were obtained. In addition, stability of electrical characteristics is significantly improved using the proposed piezoelectric harvester.

\section{Experimental Investigation of Multifrequency Energy Harvester}

Experimental investigations of mechanical and electrical characteristics were performed in order to confirm results of numerical investigation. Prototype of the energy harvester was made with the strict respect to the geometrical and physical parameters used during FEM modeling (Figure 9). 


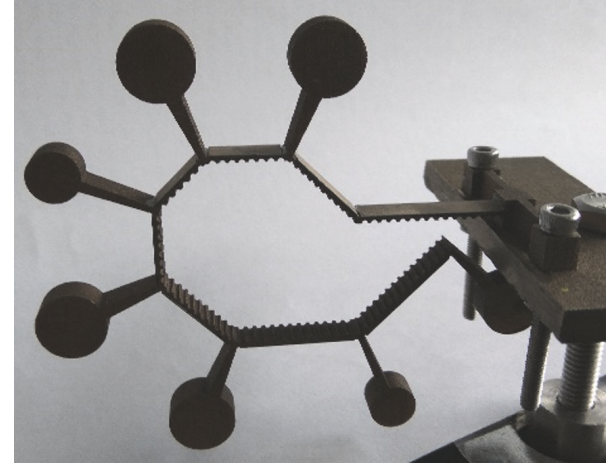

FIGURE 9: Prototype of piezoelectric energy harvester.

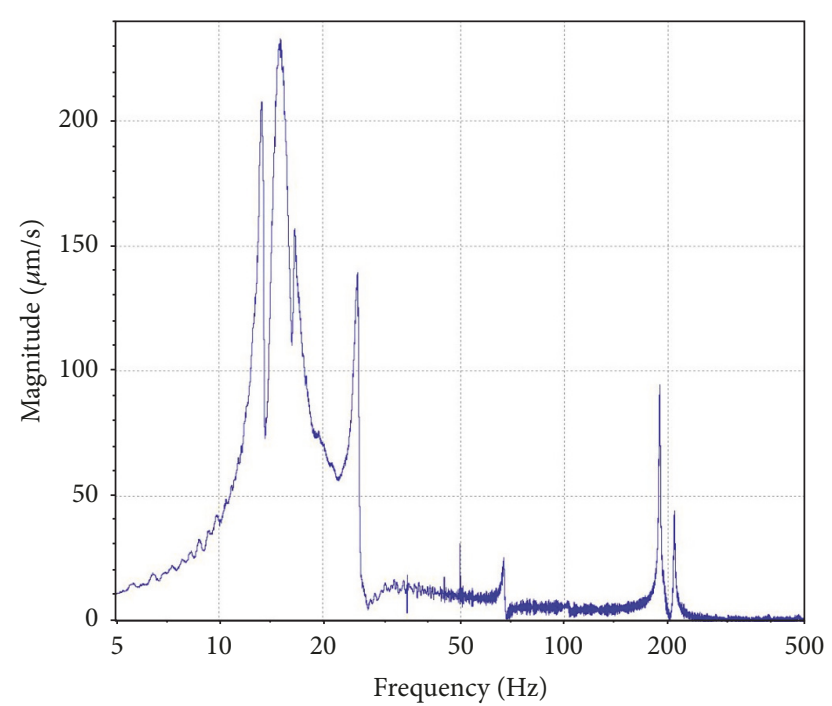

FIGURE 10: Frequency response characteristic of the energy harvester.

Firstly, experimental investigation of the frequency response characteristic was performed with the aim to validate results of numerical investigation. Polytec OFV 056 scanning vibrometer was used for acceleration measurements. Excitation of the energy harvester was performed by electromagnetic shaker Thermotron DSX-4000. A controller of Polytec vibrometer was employed to generate frequency sweep function for the shaker. Results of harvester tip acceleration measurement are shown in Figure 10.

Results of the measurement show that the energy harvester has five peaks in frequency range of $10-240 \mathrm{~Hz}$. Also, it can be seen that two additional peaks appear close to the 1st resonant frequency. This was caused by specific characteristic of the function of excitation signal. However, performed measurements confirmed results of numerical modal analysis. Differences between measured and calculated frequencies do not exceed 5.02\%. Summary of the differences between measured and calculated frequencies was made to compare obtained results (Figure 11). It can be seen that the highest difference comes at the 4th frequency and it reached

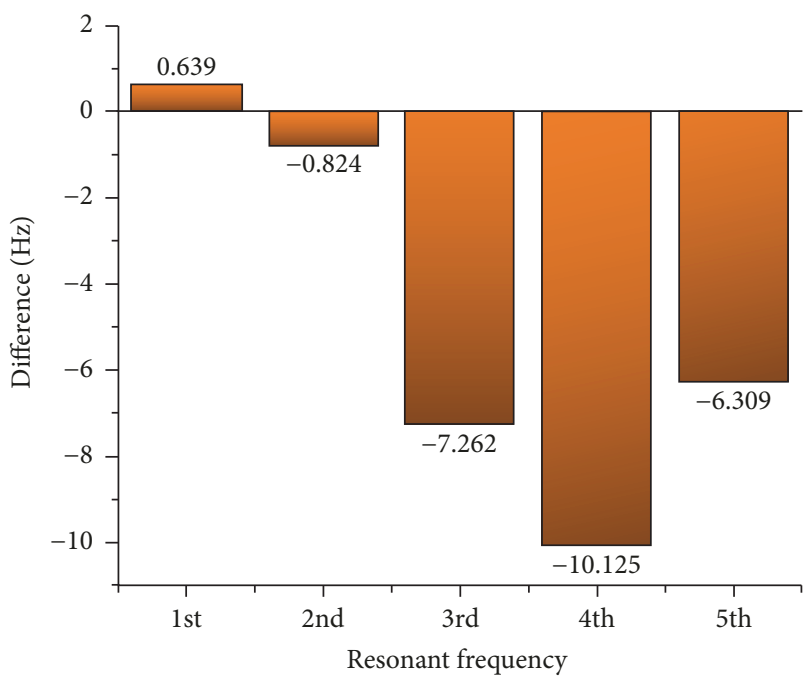

FIGURE 11: Differences between measured and calculated resonant frequencies.

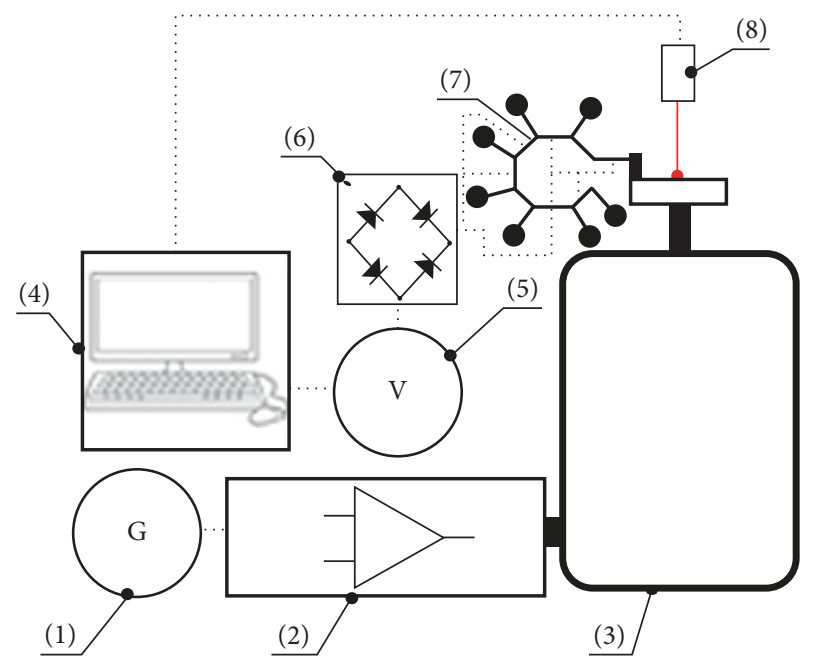

FIGURE 12: Experimental setup; (1) function generator; (2) amplifier; (3) electromagnetic shaker; (4) computer; (5) data logging multimeter; (6) electronic interface; (7) harvester; (8) displacement sensor.

10.125 Hz. Differences are caused by mismatch of materials characteristics, manufacturing errors, and slight differences in clamping.

Experimental investigation of electrical characteristics was performed as well. Output voltage density and energy density were measured in frequency range of $10-240 \mathrm{~Hz}$. Special experimental setup was built for this purpose (Figure 12).

Experimental setup consisted of function generator Tektronix AFG1062 and an amplifier that was used to drive electromagnetic shaker. Keyence LK-G155 laser sensor was used to measure base displacement, while Fluke 289 data logging multimeter was used to measure amplitude of the output voltage. Laser sensor and multimeter were connected to computer in order to record and manage data. 


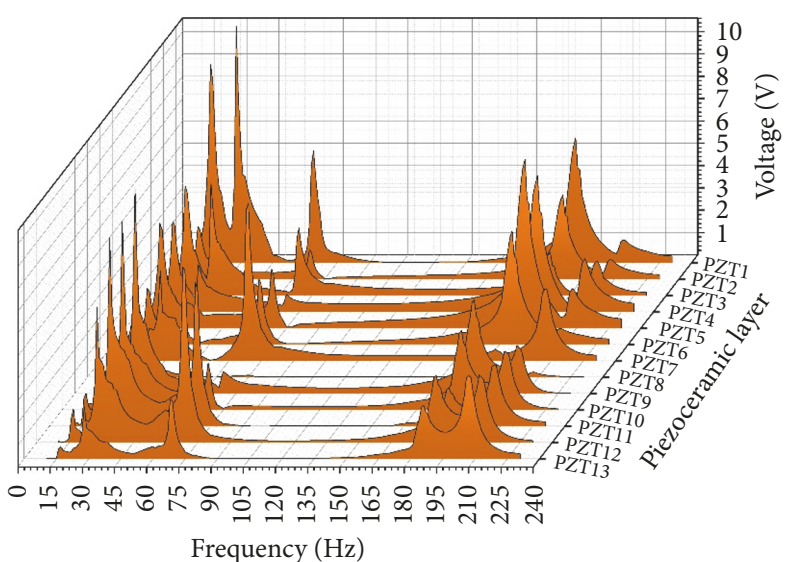

FIGURE 13: Measured output voltage of all piezoceramic layers versus frequency.

Firstly, characteristics of unrectified open-circuit voltage were measured versus excitation frequency for each piezoceramic layer. Voltmeter was connected directly to each piezoceramic layer. Base acceleration of the harvester was set to $0.475 \mathrm{~m} / \mathrm{s}^{2}$. The goal of this investigation was to indicate characteristics of unrectified open-circuit voltage for each piezoceramic layer and to assess electrical performance of the harvester. Results of measurements are given in Figure 13.

The results of measurements confirmed that all piezoceramic layers generate voltage, while harvester operates at the resonant frequencies. The highest output voltages were obtained at the low resonant frequencies. The highest output voltage was $10.61 \mathrm{~V}$ and it was generated by $\mathrm{PZT}_{1}$ layer at $25 \mathrm{~Hz}$ excitation frequency. $\mathrm{PZT}_{1}$ layer is located close to the clamped end of the harvester (Figure 3). Analysis of the results revealed that all piezoceramic layers provide output voltage at five resonant frequencies. It confirms an assumption of modal strain summation phenomena obtained through special design of the harvester. Hence, it can be noticed that all cantilevers are employed when harvester operates at resonant frequencies and it can be claimed that proposed piezoelectric harvester is more advanced compared to the conventional array of the cantilevers [25].

Next step of experimental investigation was dedicated to the measurements of total rectified output voltage density. Electronic interface was designed and connected to the energy harvester for this purpose. It consisted of thirteen full diode rectifiers. The rectifiers were made from low loss Schottky diodes BAT46 and low ESR electrolytic capacitor. Voltage density at the frequency range of $10-240 \mathrm{~Hz}$ was measured. Electronic interface was switched to the opencircuit condition; that is, electrical load was approximately equal to $10 \mathrm{M} \Omega$. Results of the measurement are shown in Figure 14.

Analysis of the voltage density graph showed that voltage density peaks are obtained at the same frequencies as in the previous measurements. It confirmed good agreement between numerical calculations and experimental measurements. Moreover, measurement shows that voltage density level is not falling below $5.25 \mathrm{mV} / \mathrm{mm}^{3}$. It means that energy

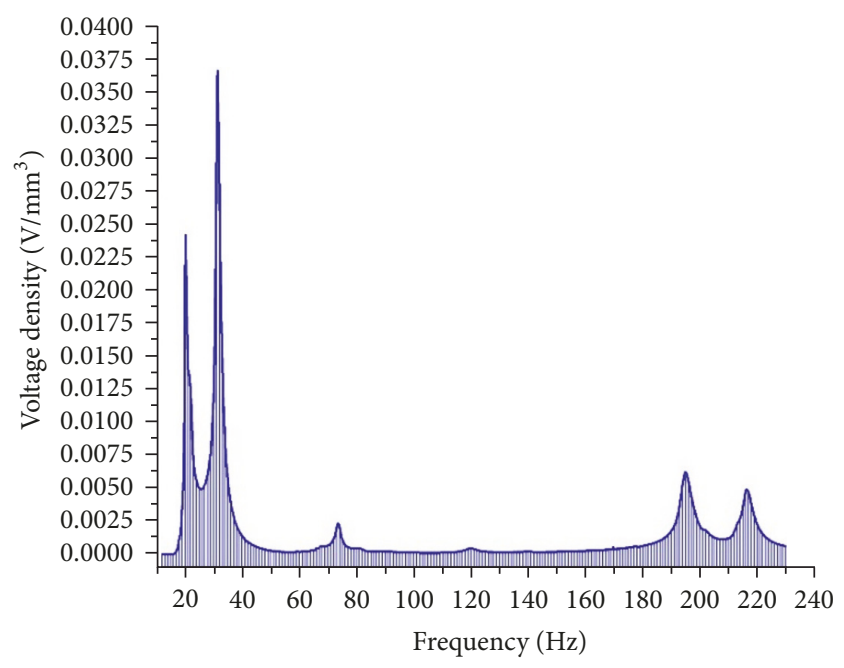

FIGURE 14: Measured voltage density in frequency domain.

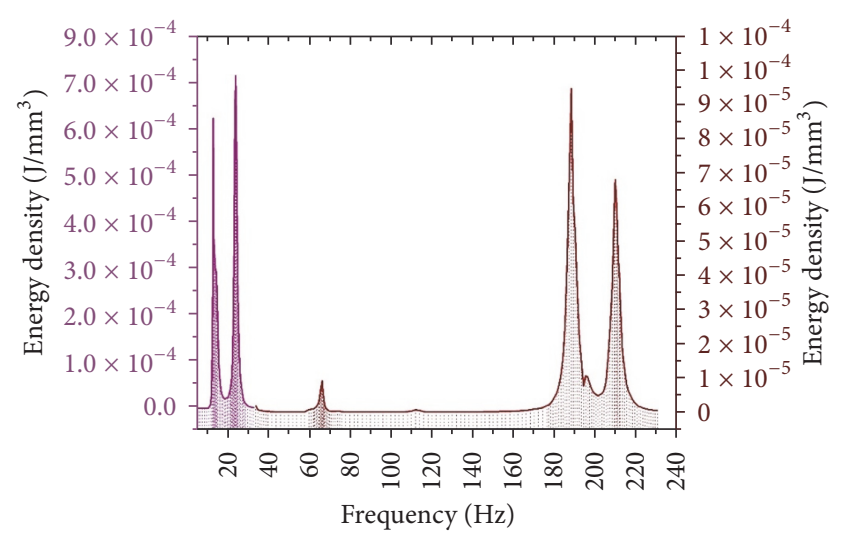

FIGURE 15: Energy density versus frequency characteristic.

harvester is able to provide sufficient voltage output at nonresonant frequency as well. The highest voltage density was obtained at the 2nd resonant frequency and it reached $37.5 \mathrm{mV} / \mathrm{mm}^{3}$. It is 7.14 times higher than lowest voltage density level. Also it can be noticed that voltage densities at the remaining four resonant frequencies are much lower than those at the 2nd resonant frequency.

Experimental investigation of energy density at the same frequency range was performed as well. The same experimental setup was used (Figure 12). The electrical interface was switched from open-circuit condition to the loaded condition. Electrolytic low ESR capacitor with capacitance of $220 \mu \mathrm{F}$ was connected as the common load. Results of the measurements are given in Figure 15. It can be seen that energy density graph has five peaks as in the case discussed before. However, peaks are slightly lower compared to the frequency response characteristic. Such mismatch can be explained by influence of capacitive load which was connected to the energy harvester through voltage rectifiers. On the other hand, shift of the resonant frequencies is relatively small, that is, $3-5 \mathrm{~Hz}$. Hence, it shows that energy 


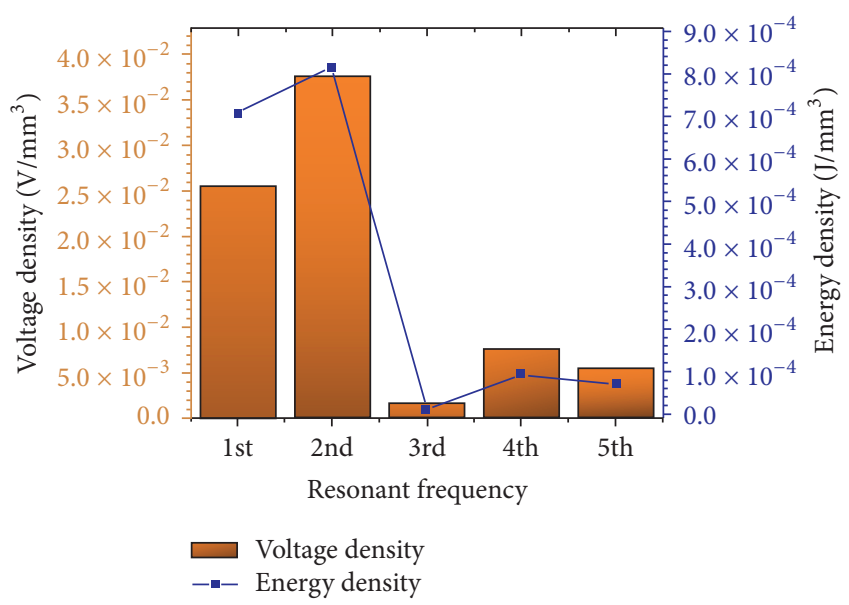

FIGURE 16: Voltage density and energy density of the harvester at the different resonant frequencies.

harvester operates sufficiently stably when capacitive load is applied.

Also it can be noticed that the highest energy density was obtained at the 2nd resonant frequency. Energy density at this frequency reached $815.16 \mu \mathrm{J} / \mathrm{mm}^{3}$. It shows that maximum output power of the proposed harvester is $65.24 \mu \mathrm{W}$ when it operates at the 2 nd resonant frequency and it is $12.68 \%$ higher value compared to the maximum output power of the conventional multifrequency cantilever array [25]. However, energy density value at the 1st resonant frequency is lower and is equal to $708.71 \mu \mathrm{J} / \mathrm{mm}^{3}$. Also, it can be seen that energy density values are much lower at the higher resonant frequencies. Energy density value reached $93.23 \mu \mathrm{J} / \mathrm{mm}^{3}$ at the 4th resonance frequency and $11.5 \mu \mathrm{J} / \mathrm{mm}^{3}$ at the $3 \mathrm{rd}$ resonant frequency. Comparison of both voltage and energy densities at the different resonant frequencies is given in Figure 16. It can be seen that energy harvesting system at the first two resonant frequencies is able to provide high energy feed to the energy storage device and even to ensure overcapacity. However, energy harvesting system provides much lower energy feed at the higher resonant frequencies.

\section{Conclusions}

A novel design of multifrequency polygon-shaped energy harvester was proposed. The modifications of cross-sectional area, additional seismic masses, and special clamping allow increasing strain of the cantilevers and improving strain distribution along the piezoceramic layers.

Numerical and experimental investigations were performed. Modal analysis showed that the system has five resonant frequencies in the range of $10-240 \mathrm{~Hz}$. The first and the second out of plane bending modes of the cantilevers are dominating in aforementioned frequency range. Moreover, numerical investigation of the strain and strain distribution showed that strain function along the piezoceramic layers is almost constant. Such strain function was achieved by modification of cross-sectional areas of the cantilevers. Numerical investigation of electrical characteristics showed that maximum voltage and energy densities were obtained at the $2 \mathrm{nd}$ resonant frequency and reached $50.03 \mathrm{mV} / \mathrm{mm}^{3}$ and $604 \mu \mathrm{J} / \mathrm{mm}^{3}$, respectively.

Experimental investigation confirmed results of the numerical modeling. The highest difference between resonant frequencies is $5.02 \%$. Moreover, experimental investigation of electrical characteristics showed that the highest voltage density and energy density were obtained at the 2nd resonant frequency. Both voltage and energy densities reached $37.5 \mathrm{mV} / \mathrm{mm}^{3}$ and $815.16 \mu \mathrm{J} / \mathrm{mm}^{3}$, respectively. Maximum output power of the harvester is $65.24 \mu \mathrm{W}$. Finally, it can be concluded that proposed piezoelectric energy harvester is able to provide suitable energy feed through multifrequency operation principle.

\section{Conflicts of Interest}

The authors declare that there are no conflicts of interest regarding the publication of this paper.

\section{References}

[1] T. Y. Kheng, Energy Harvesting Autonomous Sensor Systems: Design, Analysis and Practical Implementation, Taylor \& Francis, 2012.

[2] D. Spreemann and Y. Manoli, Electromagnetic Vibration Energy Harvesting Devices, Springer Science + Business Media, New York, NY, USA, 2012.

[3] S. Roundy, P. K. Wright, and J. M. Rabaey, Energy Scavenging for Wireless Sensor Networks, Springer Science + Business Media, New York, NY, USA, 2004.

[4] N. Elvin and A. Erturk, Advances in Energy Harvesting Methods, Springer Science + Business Media, New York, NY, USA, 2013.

[5] S. Priya and D. J. Inman, Energy Harvesting Technologies, Springer Science + Business Media, New York, NY, USA, 2009.

[6] D. Spreemanm and Y. Manoli, Electromagnetic Vibration Energy Harvesting Devices, Springer Science + Business Media, New York, NY, USA, 2012.

[7] S. Roundy, P. K. Wright, and J. M. Rabaey, Energy Scavenging for Wireless Sensor Networks with Special Focus on Vibrations, Springer Science + Business Media, New York, NY, USA, 2004.

[8] T. J. Kazmierski and S. Beeby, Nergy Harvesting Systems, Springer Science + Business Media, New York, NY, USA, 2011.

[9] A. Erturk and D. J. Inman, Piezoelectric Energy Harvesting, John Wiley and Sons, Hoboken, NJ, USA, 2011.

[10] A. Erturk and D. J. Inman, "On mechanical modeling of cantilevered piezoelectric vibration energy harvesters," Journal of Intelligent Material Systems and Structures, vol. 19, no. 11, pp. 1311-1325, 2008.

[11] M. J. Guan and W. H. Liao, "On the equivalent circuit models of piezoelectric ceramics," Ferroelectrics, vol. 386, no. 1, pp. 77-87, 2009.

[12] T. Yildirim, M. H. Ghayesh, W. Li, and G. Alici, "A review on performance enhancement techniques for ambient vibration energy harvesters," Renewable \& Sustainable Energy Reviews, vol. 71, pp. 435-449, 2017.

[13] W. Al-Ashtari, M. Hunstig, T. Hemsel, and W. Sextro, "Increasing the power of piezoelectric energy harvesters by magnetic stiffening," Journal of Intelligent Material Systems and Structures, vol. 24, no. 11, pp. 1332-1342, 2013. 
[14] L. Tang, Y. Yang, and C. K. Soh, "Toward broadband vibrationbased energy harvesting," Journal of Intelligent Material Systems and Structures, vol. 21, no. 18, pp. 1867-1897, 2010.

[15] E. S. Leland and P. K. Wright, "Resonance tuning of piezoelectric vibration energy scavenging generators using compressive axial preload," Smart Materials and Structures, vol. 15, no. 5, article no. 030, pp. 1413-1420, 2006.

[16] G. Wang, W. H. Liao, B. Yang, X. Wang, W. Xu, and X. Li, "Dynamic and energetic characteristics of a bistable piezoelectric vibration energy harvester with an elastic magnifier," Mechanical Systems and Signal Processing, vol. 105, pp. 427-446, 2018.

[17] X.-Y. Jiang, H.-X. Zou, and W.-M. Zhang, "Design and analysis of a multi-step piezoelectric energy harvester using buckled beam driven by magnetic excitation," Energy Conversion and Management, vol. 145, pp. 129-137, 2017.

[18] D. Upadrashta and Y. Yang, "Nonlinear piezomagnetoelastic harvester array for broadband energy harvesting," Journal of Applied Physics, vol. 120, no. 5, Article ID 054504, 2016.

[19] W. Zhou, G. R. Penamalli, and L. Zuo, "An efficient vibration energy harvester with a multi-mode dynamic magnifier," Smart Materials and Structures, vol. 21, no. 1, Article ID 015014, 2012.

[20] S. Lee, B. D. Youn, and B. C. Jung, "Robust segment-type energy harvester and its application to a wireless sensor," Smart Materials and Structures, vol. 18, no. 9, Article ID 095021, 2009.

[21] S. Qi, R. Shuttleworth, S. O. Oyadiji, and J. Wright, "Design of a multiresonant beam for broadband piezoelectric energy harvesting," Smart Materials and Structures, vol. 19, no. 9, Article ID 094009, 2010.

[22] M. Rezaeisaray, M. E. Gowini, D. Sameoto, D. Raboud, and W. Moussa, "Low frequency piezoelectric energy harvesting at multi vibration mode shapes," Sensors and Actuators A: Physical, vol. 228, pp. 104-111, 2015.

[23] R. M. Toyabur, M. Salauddin, and J. Y. Park, "Design and experiment of piezoelectric multimodal energy harvester for low frequency vibration," Ceramics International, vol. 43, pp. S675-S681, 2017.

[24] S. Dhote, Z. Yang, and J. Zu, "Modeling and experimental parametric study of a tri-leg compliant orthoplanar spring based multi-mode piezoelectric energy harvester," Mechanical Systems and Signal Processing, vol. 98, pp. 268-280, 2018.

[25] H. Xue, Y. Hu, and Q.-M. Wang, "Broadband piezoelectric energy harvesting devices using multiple bimorphs with different operating frequencies," IEEE Transactions on Ultrasonics, Ferroelectrics and Frequency Control, vol. 55, no. 9, pp. 21042108, 2008. 


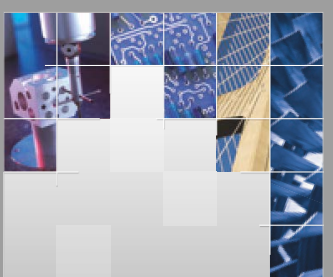

\section{Enfincering}
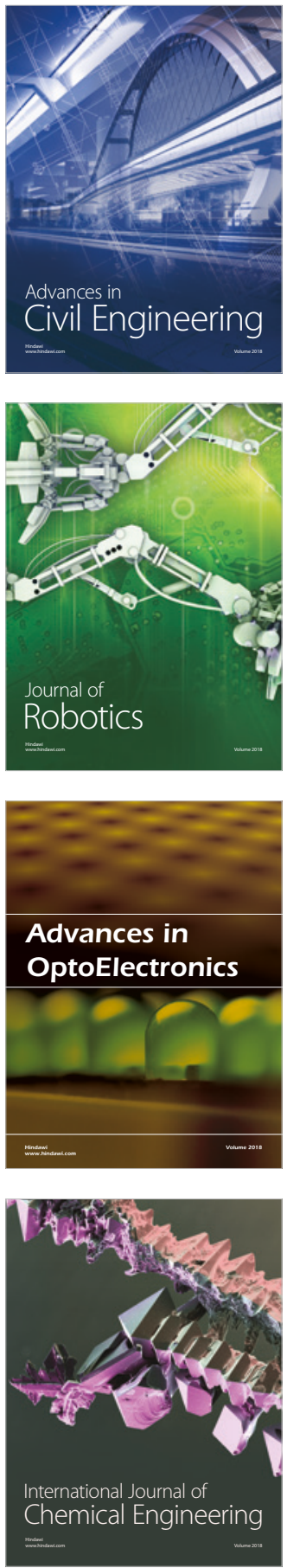

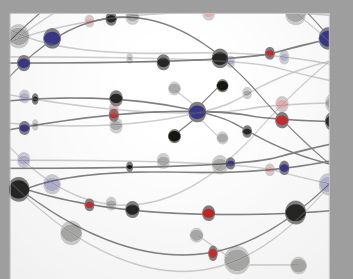

\section{Rotating \\ Machinery}

The Scientific World Journal

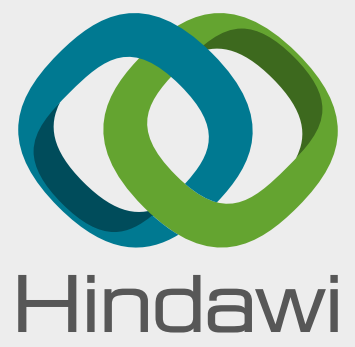

Submit your manuscripts at

www.hindawi.com
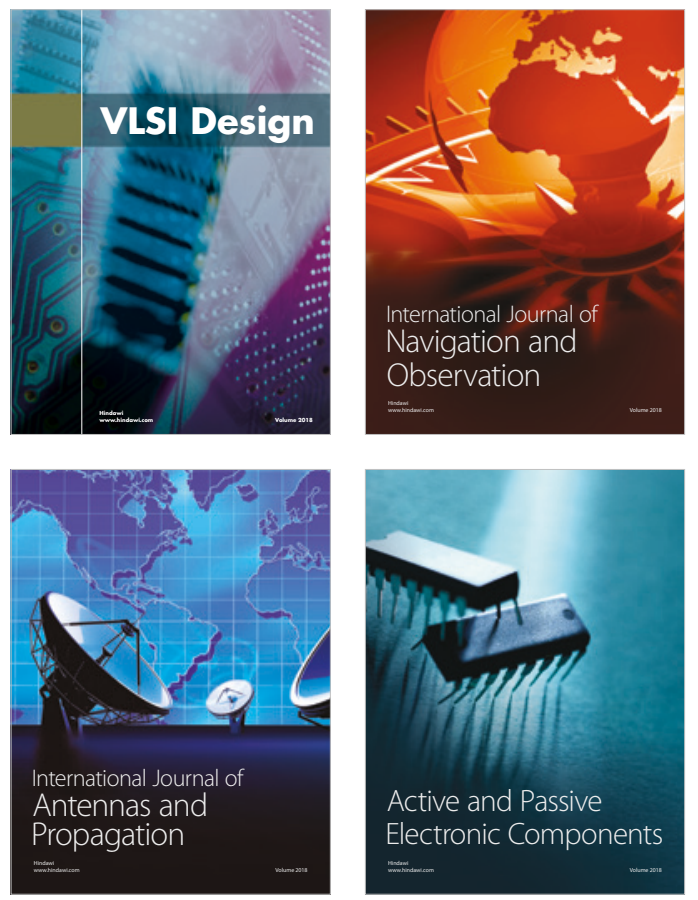
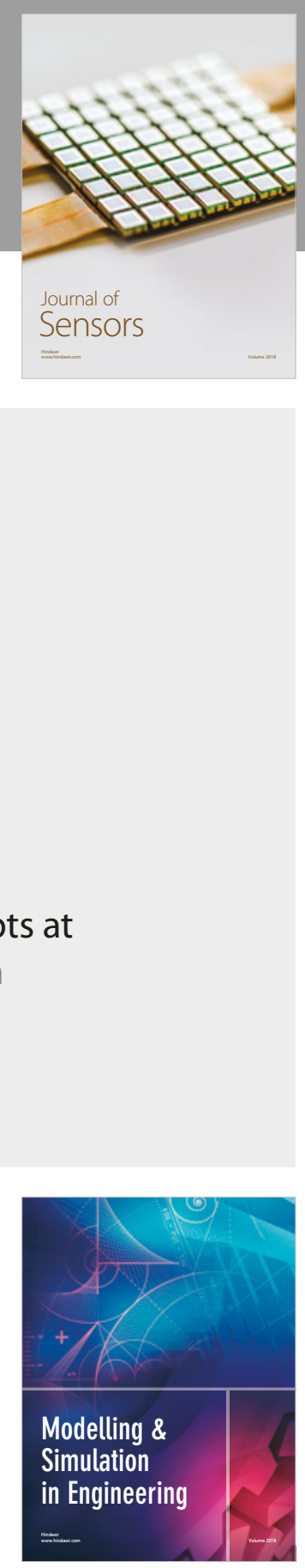

\section{Advances \\ Multimedia}
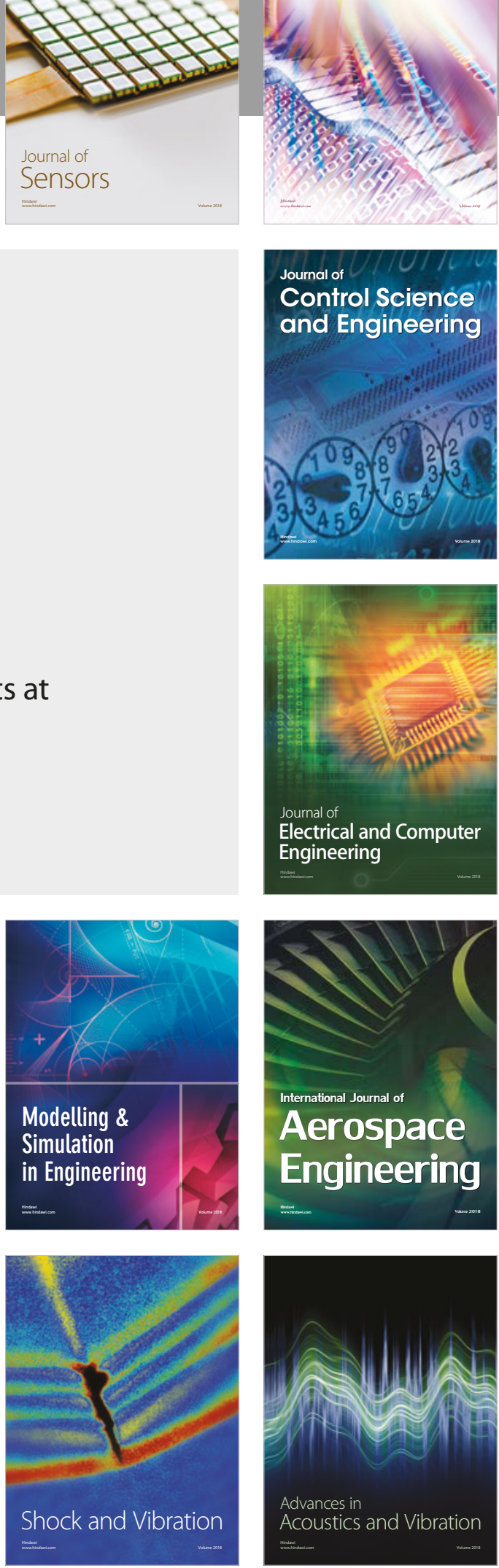